\title{
COTIDIANO ACADÊMICO E PATRIMÔNIO UNIVERSITÁRIO: RITMOS DE DURAÇÃO NA CIDADE
}

\author{
Ana Luiza Carvalho da Rocha \\ Cornelia Eckert
}

\section{Patrimônio edificado ou razões simbólicas para continuar}

Certamente o valor da atividade acadêmica no mundo contemporâneo não se resume aos diplomas conferidos ou títulos publicados pelos cientistas, mas igualmente reside na sua contribuição para a defesa de territórios-mitos guardiões do sistema simbólico de referência identitária cultural e da memória coletiva de um povo. Como sugere Anthony Giddens, um dos mais citados cientistas sociais da contemporaneidade, em face da negligência de políticas urbanas em relação ao patrimônio material e imaterial, importa cada vez mais estarmos atentos para a sustentabilidade das formas de criação e recriação do senso de identidade de indivíduos e grupos. Portanto, segundo este autor, a condição contemporânea do viver urbano nos remete sistematicamente à amnésia coletiva pela ameaça das perdas de referências de imagem e pela fragmentação das formas de sociabilidade e complexidades institucionais que organizam o mundo social. A ameaça ao esquecimento não é, entretanto uma condição presente.

A existência do patrimônio material e o reconhecimento de patrimônios imateriais por parte das políticas públicas permitem o conhecimento dos habitantes citadinos de seus percursos históricos e promovem a consciência do viver social. Uma consciência coletiva que não só depende da memória construída, mas contribui para a memória social e coletiva dos cidadãos. Como afirmava Píndaro "O homem é um ser que esquece”, sobretudo esquecem de si mesmos, de reiterar uma imagem de si na riqueza das interações de reciprocidade humana. Neste ponto, o tema do "fantasma do esquecimento", tão caro à obra do filósofo alemão Walter Benjamin, anuncia, de forma comovente, o sentimento de "crise da civilização" que se manifesta na crise epistemológica das "ciências do homem" geradas no mundo contemporâneo. 
Ao longo das imensas rupturas e descontinuidades provocadas por revoluções tecnológicas e científicas do séc. XX, dos quais somos tributários em nossa "arte de pensar" o mundo e o tempo, não é ao acaso que se constata que a abordagem etnográfica e social dos bens patrimoniais tangíveis e intangíveis reflete sobre a vida e a matéria, atribuindo ao ato de conhecer dos habitantes das grandes cidades o ato de interagir com a sua história. Em antropologia urbana, o ato de viver a cidade moderna, urbano-industrial, comporta, para os seus habitantes, o ato de narrar suas histórias vividas neste espaço; histórias que apontam para as diferenças e alteridades que constituem uma comunidade urbana.

Parte integrante do dispositivo simbólico humano, como a linguagem e a técnica, a cidade moderna apresenta variações em torno de um mesmo motivo: a domesticação do tempo e do espaço através de símbolos. Assim, se em certos centros urbanos o ato de restaurar e conservar edificações são formas encontradas por seus habitantes para domesticar a passagem do tempo, fazendo da cidade um "cemitério de civilizações", em outros, a adesão ao ritmo de inovações e modernizações impõe a destruição de antigos casarios, velhos bairros e paisagens de arrabaldes, na busca de recriar o caos primordial onde se celebra, com vigor, o renascimento de um novo corpo coletivo.

Portanto, no contexto, das grandes civilizações urbanas, o gesto do esquecimento (ruína) ou do desejo de transformação no "reformado" e revestido (domesticação da força efêmera do tempo e negação da morte), pode ser compreendido como o trabalho de deslocar o explícito (alegoria da caducidade) ${ }^{1}$ em uma nova ordem de significado, gerando um sentido outro para a instabilidade estética agora satisfatória e conciliadora com a obra do tempo descontínuo. Na lógica de uma memória moderna, pode-se encontrar aqui a tessitura da duração no cotidiano do lugar, implícita no ato do esquecimento (abandonar, destruir, restaurar).

Reiterar a importância da permanência do patrimônio gerado pela vida universitária na cidade de Porto Alegre é reivindicar a duração de parte da matéria onde repousam as experiências de trajetórias de seus ex-alunos. Lembranças de uma cultura letrada que transmitidas na forma de patrimônio artístico, tecnológicos e intelectuais às novas gerações, tem alimentado não só a prática e ação de rememorar a sabedoria de gerações, o que se traduz

\footnotetext{
${ }^{1}$ Inspiramo-nos em Walter Benjamin "que no lugar de conceitos, nos apresenta imagens” (1972:346)
} 
por uma atitude espiritual que envolve diretamente rituais cotidianos que são fundamentais para que a ameaça de esquecimento seja dissipada ${ }^{2}$, mas nutre igualmente a história da cultura escolar e universitária de um contexto urbano.

As propostas hoje na defesa patrimonial nos conduz a refletir sobre a dialética suis generis na forma de como é possível se operar com a dimensão ética e estética dos estudos da memória (valores, crenças, tradições, visões de mundo e estilos de vida diferenciais, nos grandes centros urbano-industriais.

Significa pensar a história de uma instituição de ensino no contexto da sociedade abrangente contemporânea como reservatório concreto e efetivo de memórias coletivas e de vontades de indivíduos e grupos que, compartilhando um mesmo território plural de existência, agem em conjunto e reinventam cotidianamente a sua condição humana primordial, na busca de eternizar-se no tempo.

Buscando contribuir para a tradição acadêmica de refletir sobre a memória coletiva nas cidades brasileiras, desenvolvemos pesquisa sobre memórias coletivas e itinerários urbanos em Porto Alegre e outras cidades do Estado do Rio Grande do Sul, através do projeto BIEV sediado no Instituto ILEA. E é deste lugar que tecemos aqui considerações sobre a importância etnográfica dos estudos de patrimônio urbano.

\section{Se as idéias que sugerimos constituem-se em patrimônio imaterial da UFRGS, de que memória universitária estamos falando?}

Memória da UFRGS é o título de uma obra publicada com os depoimentos de inúmeros professores e/ou ex-alunos que narram eventos e experiências que colocam em alto relevo seus sentimentos de pertença ao contexto universitário.

Todos os depoimentos convergem em construir, nestas narrativas escritas, o relato das trajetórias e experiências de diferentes gerações. Seja tratando dos primórdios históricos da Universidade, seja tratando dos tempos difíceis pelos limites de liberdade de expressão nas conjunturas ditatoriais, nunca foi possível, pondera a historiadora Helga Picollo "calar a Universidade" (In: Guedes e Sanguinetti, 1994: 35). Cada depoimento, dos inúmeros publicados e outros apenas gravados, apontam para uma Universidade em sistemático

2 Mircea ELIADE, em sua obra clássica, Le mythe de l'éternel retour, 1982, analisa aqui o tempo como sagrado por sua qualidade de 
processo de construção, estruturação ou re-construção e re-estruturação de sua política educacional de sua estrutura universitária, de sua organização pedagógica, seus projetos de pesquisa e de consolidação da produção incessante do conhecimento científico.

Carregado de emoção pelas lembranças do passado, o depoimento de Lauro Hagemann ou as lembranças do ex-reitor Tuiskon Dick (em relato pessoal) acentuam trajetórias iniciadas em casas de estudante universitárias. Infra-estrutura necessária para abrigar uma população diversa oriunda de localidades interioranas, tendo no ensejo do curso universitário gratuito em instituição federal, o projeto possível de aquisição de capital cultural e conhecimento científico.

Em 1956, o professor Hagemann ingressou nos quadros da Rádio Universitária como redator, um dos prédios adotados no conjunto arquitetônico de recuperação. Relatando as dificuldades iniciais de desenvolvimento do projeto de radiofusão universitária, o jornalista pondera que mesmo que ainda hoje a Universidade lhe parece um "monstro sagrado": "hoje vejo-a como uma instituição necessária, uma conquista da sociedade”. Segue o professor:

\footnotetext{
"O saber, o conhecimento, todos os avanços do homem sobre a face do planeta são conseqüência do acúmulo e da transmissão do conhecimento e esse conhecimento não pode ser vendido nem comprado, ele é um patrimônio comum da sociedade humana e a Universidade representa o ápice dessa conquista” (In: Guedes e Sanguinetti, 1994: 339).
}

Tempos de construção, de esperanças e de utopias, como se refere o Professor Gervásio Rodrigo Neves (In: Guedes e Sanguinetti, 1994: 49), o tempo de "passar" na experiência universitária, sugere que os citadinos de uma forma ou de outra descobrem profundas relações com as instituições nas quais agem ou se relacionam.

Mas inserir-se na Universidade de alguma forma, diretamente como servidor ou como aluno, ou como simples relação urbana compartilhada, infere na consciência de um tempo passado. A instituição já estava lá, suas práticas já estavam estruturadas e o processo universitário já se situa como uma realidade construída para cada novo ingressante. 
Recorrendo a nossa própria experiência vivida, respectivamente em 1975 e 1976, podemos reconhecer estas passagens rituais de ingresso na organização educacional. Constituir-se como sujeito universitário é esta adesão cotidiana ao universo cultural e geracional em que a socialização se dá pela interação em salas de aulas, pela organização em grupos de estudo, em vencimento de etapas e curriculuns para uma feliz continuidade como profissionais de pesquisa em antropologia.

Este espelhamento de nossas próprias trajetórias se entrelaça a tantas outras que estetizam uma paisagem de pertencimentos, afetivos ou conflitivos, como desenham os relatos de Enio Squeff (Não somos apenas a utopia) de Raul Pont (O Bar da Filô) de Pedro Cezar Dutra Fonseca (Breve reencontro com a primeira pessoa), ou de Gilka Girardelo (Pelas beiradas da UFRGS) entre tantos outros depoimentos, para entender-se a complexa rede de relações que um patrimônio universitário como da UFRGS abriga. Como se expressa Girardelo "muito mais gente vive uma universidade do que sugerem suas listas de diplomados” (In: Guedes e Sanguinetti, 1994: 82)

A história de cada indivíduo na UFRGS é igualmente a história das situações que ele traçou nos territórios urbanos, na cidade de Porto Alegre, no Campus Centro, no Campus médico, no Campus do Vale, e é a ação desse sujeito nesses espaços que faz de cada episódio banal uma situação para ele de reinvenção de suas tradições, de seus sentimentos de pertença, de projeto social.

É por isso que concebemos a narrativa da estética dos fenômenos culturais como vinculadores dos estilos de conhecer e viver nas cidades, que acomodam os jogos da memória de sua comunidade não só universitária, mas urbana de modo geral. O patrimônio edificado ainda hoje existente no Campus Centro da UFRGS representa, portanto, parte da construção social e histórica dos saberes técnicos e científicos que construíram o próprio patrimônio edificado local.

As obras de inúmeros arquitetos e engenheiros tanto quanto artistas plásticos e urbanistas formados nos bancos desta universidade foram, e ainda são, hoje, as marcas visíveis do entrelaçamento da memória deste território na conformação da atual paisagem urbana na cidade. É interessante parar para pensar sobre este espaço em que nos encontramos cotidianamente para nossas atividades acadêmicas. Que lugar patrimonial é este? Trata-se de 
um contexto universitário e o vivemos rotineiramente quase sem apreende-lo enquanto um lugar patrimonial, de formação de geração de cientistas sociais. Seja no Instituto de Filosofia e Ciências Humanas a que pertencemos seja no Instituto Latino Americano de Estudos Avançados que nos abriga, estamos no denominado "campus central da UFRGS" e seu conjunto de prédios ultrapassa, assim, seu valor arquitetônico propriamente dito. Que estilo nos acolhe? Modernos, funcional, estilo anos 1970, também o campus centro vai constituindo história patrimonial junto ao espaço de origem de tudo, o campus Centro que concentra a própria memória das formas urbanas que, ainda hoje, caracterizam a cidade Porto Alegre, posto que o espaço conformado pela paisagem dos prédios do Campus Centro da UFRGS nos permitem remontar épocas diferenciadas das práticas culturais de seus usuários.

Aderimos aqui a uma posição cultural e política de preservação do conjunto arquitetônico da UFRGS e em especial ao patrimônio que permite dimensionar o território mito e patrimônio etnológico urbano local como uma obra moldada e configurada pelo depósito de muitos gestos e intenções dos grupos humanos que nela habitam, em especial, dos técnicos e dos profissionais formados por esta universidade.

$\mathrm{Na}$ linha dos trabalhos do historiador Michel De Certeau, talvez não seja inútil sublinhar a importância do domínio desta história do cotidiano, do "invisível", que insere o espaço universitário cotidiano na história urbana e industrial portoalegrense a partir da memória das práticas e dos saberes técnicos e científicos, e que irão reverter para a vida citadina local na criação de sua paisagem arquitetônica singular.

Pensar a matéria objetiva da memória coletiva que encerram as práticas culturais e sociais na área central de Porto Alegre é pensar o conjunto das edificações que nos abrigam. Como se pode constatar, sua importância é tal que estes espaços chegam a moldar, de forma decisiva, a noção de lugares de pertença (veste-se a camiseta) em contexto público onde se desenrolam importantes acontecimentos da vida urbana local. Um tal território possui, portanto, uma "assinatura", aquela inscrita pela história de seus usuários, representando por tais motivos seu laço de pertença a vida urbana portoalegrense.

Pertencer a uma geração de alunos, de professores ou de funcionários nos identifica aos contornos de um patrimônio universitário como um lugar de reconhecimento que parte de um dispositivo social e cultural segundo o qual o espaço urbano portoalegrense se torna 
um objeto de conhecimento para as comunidades urbanas locais, que "possuem", assim, por sua vez, um direito a ele.

Defendemos aqui, portanto, uma linha de argumentação que sustenta a necessidade da reabilitação da idéia do patrimônio histórico, artístico e arquitetônico nos termos de um patrimônio etnológico, ou seja, que tenha por base as heterodoxias do passado, salvaguardando o essencial de uma memória coletiva urbana, segundo a multiplicidade de seus suportes e a imensa vitalidade silenciosa de seus símbolos. Não se trata mais de pensar o respeito aos objetos restaurados, mas aos beneficiários da restauração. Nesta política de autores, os habitantes das grandes cidades e seus sistemas de práticas devem ser valorizados ao invés de desapropriá-los de seus objetos de lembranças como normalmente ocorre na “economia da restauração", segundo suas leis de mercado.

Numa "prospectiva urbana", este nosso depoimento para atentarmos ao nosso espaço cotidiano de pertença acadêmica, caracteriza-se como parte integrante das cadeias de gestos e relatos de inúmeros habitantes da cidade de Porto Alegre, reconhecendo-se neles as próprias invenções de saberes e fazeres tecnológicos responsáveis pela modernização de sua paisagem urbana e industrial tal qual a conhecemos hoje.

Inspirados mais uma vez em De Certeau, afirmamos que as histórias dos lugares é que os tornam "habitáveis" e sem estas histórias eles se tornam desertos. Por outro lado, ao arrancar os registros de memórias dos "solos onde desabrocham”, é destruir parte deste processo; fomentar ou restaurar esta narratividade é, portanto, também tarefa de restauração.

\section{No passado, tudo era no "centro"}

Nossas primeiras aulas como alunas do curso de Ciências Sociais e de História, respectivamente, nos idos anos 1970, se deram no antigo prédio da Filosofia como é hoje reconhecido o prédio ao lado da Reitoria.

Naquela época a UFRGS se concentrava privilegiadamente no campus Centro no seio da capital "localizado em área nobre no coração de Porto Alegre, formado por edifícios, quase 
todos monumentais, ainda hoje abrigando dependências didáticas da UFRGS” (Soares, 1986 apud: Hassen 1996:90).

No seu surgimento, a novidade arquitetônica transformou a paisagem porto alegrense caracterizada ainda por ruas estreitas, com calçamentos irregulares. Uma matéria do Diário de Notícias de 1935 noticias estas mudanças estéticas:

"A cidade da universidade de Porto Alegre (...) Velhos pardieiros foram demolidos e em seu lugar construídos prédios majestosos, alguns arranha-céus e edifícios de belas linhas arquitetônicas. Bairros inteiros se formaram e o número de construções novas aumentava cada vez mais (...)”.(In: Hassen 1996:107)

Os medos urbanos da época conheciam na higienização, na iluminação, na urbanização, na industrialização, enfim, na modernização, os ideais de uma sociedade engajada a progredir na flecha progressista do tempo. A Porto Alegre da belle époque constrói aos poucos os símbolos que qualificam seu ethos e habitus cotidianos: o footing ${ }^{3}$ na rua da praia, os cafés os bondes, os bailes na reitoria da UFRGS, as reuniões dançantes no CEUE da Medicina ou Odontologia, as formaturas pomposas abrigando figurinos da época e etiquetas singulares de uma camada média que conquista na conjuntura getulista, a realização de projetos de ascensão social e cultural $^{4}$ na consumação de faculdades e cursos técnicos promovidos pela UFRGS.

O Campus Centro torna-se logo espaço de rotinas, cotidianos acadêmicos, mas também de efervescências políticas lembradas nos documentos históricos e nos depoimentos de ex-professores e ex-alunos. Seja nos cem anos da Revolução Farroupilha, festejos abrigados no campo da Redenção atingindo a área do campus universitário com eventos e comemorações; seja nos anos de chumbo com a dramática ruptura da liberdade de pensamento e de expressão, o espaço do campus é cenário da cultura política.

\footnotetext{
3 "O chamado footing na Rua da Praia, era antigo hábito entre rapazes e moças, que perdurou em Porto Alegre até os anos 60. Consistia em passeios, a determinadas horas, sem maiores compromissos, a não ser tentar algum namoro, ver o movimento ou por simples passatempo". Almanaque Gaúcho, “Túnel do Tempo" de Antônio Goulart. Zero Hora. Porto Alegre, 23 de outubro de 2000. p. 54

4 Seguimos os preceitos de Pierre Bourdieu para quem a noção de classe social ou "segmentos médios" deve ser apreendida tanto a partir da posição e situação na estrutura social quanto dos bens simbólicos e do capital cultural referentes às relações entre as classes, uma vez que se relacionam ao mundo representacional que os atores conferem a suas posições de pertencimento. (Bourdieu, 1974).
} 
A Universidade que nascera para o diálogo aos discípulos conhecia na dramática do terror, o lugar da proibição, da vigilância da fala, do olhar, do escutar clandestino, ameaçado pela repressão e prática da tortura ditatorial. Como testemunha o presidente do CEUE entre 1972 e 73, engenheiro Pedro Bisch Neto, “a grande tarefa era ainda manter o movimento acadêmico, era tentar a todo custo salvar o que era possível” (In: Hassen, 1996:169), sem dúvida uma época fatídica, relata Bruno Mendonça Costa, médico pela UFRGS e presidente da FEURGS anos 1960, que marcou a trajetória profissional e política de toda uma geração. Afinal, testemunha esta geração, estes anos são tempos de "caça as bruxas", de ditadura, de AI-5 (Costa Guedes e Sanguinetti, 1994: 83), de expulsão de professores, de desaparecimento de alunos, mas igualmente de indignação que alimenta uma cultura universitária que socializa uma nova geração contra-hegemônica.

As reformas universitárias são executadas, como a promulgação da Lei 5.540 de 28 de novembro de 1968 que fixava, então sob a jurisdição do Ministro da Educação Tarso Dutra, "as normas de organização e funcionamento de ensino superior, lei que até hoje rege a Universidade brasileira" (Leite In IFCH, 1993:83). Em seguida, em 1969, era introduzido o regime de trabalho integral do corpo docente, valorizando a produção departamental e os cursos de pós-graduação stricto sensu.

O espaço da Universidade vai, assim, abrigando uma geração inquieta e transformada pela internacionalidade de novos paradigmas e padrões culturais: o movimento feminino internacional, o movimento sindical internacional, o movimento estudantil internacional, os movimentos nacionalistas, tudo gera um senso crítico de base universal e popular. $\mathrm{O}$ espaço da Universidade é o lócus de debates por mudança, de organizações e movimentos que buscam no confronto ao poder estatal, sair da invisibilidade para promover o conhecimento da situação social e política de um país. Bruno Mendonça Costa relata a transformação das atitudes nos campus universitários na época "Greves, discursos em todos os níveis, discussões intermináveis sobre os objetivos de uma universidade num país subdesenvolvido" (Idem:84). Erico Veríssimo, contam os relatos, recusou o título de Doutor Honoris Causa que a reitoria de 1968 a 1972 queria lhe conferir. Publicamente divulga sua recusa como recriminação aos interesses dirigentes da Universidade que partilhavam de projetos da ditadura militar e aderiam às reformas de ensino segundo modelos referendados pelo governo norte-americano 
(em 1972 a UFRGS remodela-se pelo acordo MEC-USAID), sem uma postura crítica e avaliativa.

O espaço do Campus Centro, em torno do RU, do Bar da Filô, dos corredores da Faculdade de Arquitetura e da Engenharia, o DCE da UFRGS, estudantes e professores buscavam lidar com o medo da repressão. A morte de um estudante de Engenharia da UFRGS em 1970, preso pela DOPS-RS em 1969 (Matzenbahcer In: Costa Guedes e Sanguinetti, 1994: 148) a todos indignava, pois mais um nome se inscrevia numa longa lista de calados, presos e torturados nos centros de teatros, em instituições jornalísticas, em escolas, em igrejas, nos bastidores políticos, nos subterrâneos da cidade. Não denunciar o colega, foi para muitos o único pequeno gesto de resistência face os inquéritos a que muitos foram coagidos. É nesta ambiência de desconfianças e insegurança que para tantos outros restou a fuga, o exílio, para apenas anos mais tarde, no sopro de tempos mais democráticos retornarem como professores (recorrer a Costa Guedes e Sanguinetti, 1994), sendo que muitos, nos últimos anos e hoje, destacam-se no quadro político nacional.

No fluxo da abertura democrática nacional, a representação estudantil ganha proporcionalidade nos órgãos diretivos, as federações e sindicatos se solidificam em representar a cidade universitária frente a comunidade jurídica e política. Pequenos atos de rebeldia vão conquistando destaque na imprensa citadina: "mais restaurantes", "pela qualidade de ensino", "por uma casa de estudante mista", "pela volta de professores cassados", "por uma biblioteca central ou pelo patrimônio universitário", as manifestações tomam formas mais administrativas e institucionais nas escolhas proporcionais de diretores, reitores e outros representantes. Nem sempre respeitada, como demonstra o acontecimento ocorrido em setembro de 1988 definido pelo noticiário jornalístico como "triste episódio" pela reação da classe estudantil à escolha, por parte do Ministério da Educação, do segundo professor indicado a cargo de reitor em lista sextupla, tendo os alunos invadido o CONSUN com a reação, pela primeira vez, da política adentrando no espaço universitário para contenção da discórdia, uma "tragicomédia" define Henrique Castro frente ao incidente (In: Costa Guedes e Sanguinetti, 1994: 163).

Mas a Universitas toma forma e gosto com os novos ares democráticos e cede a demanda de novos campos profissionais, novas especializações e maior número de vagas para a cidade. 
Programas de pós-graduação e uma estrutura de pesquisa científica se institucionalizam voltado para a formação de cientistas brasileiros. Os salões de iniciação científica se proliferam nas salas da Arquitetura, da Educação, da Medicina, da Engenharia, etc. Certamente, como o relata o premiado Prof. Salzano "da Genética”, "fazer ciência no Brasil ainda é uma questão de heroísmo. As verbas disponíveis são reduzidas e geralmente chegam tarde, problemas simples de infra-estrutura não são apropriadamente resolvidos, e vive-se em constante sobressalto". Mas esta parece ser a dinâmica da produção acadêmica em um país de dependências econômicas, pondera o professor, tendo neste valor -heroicidade

- o re-encontro com a arte de saber-fazer, de transmitir e gerir novos conhecimentos ao gratificar-se com "o acompanhamento da formação e crescimento intelectual dos jovens" (Salzano. In: Guedes e Sanguinetti, 1994: 214).

Ambiente de troca, de camaradagem, de debate, de criação, o topos universitário se abre e é aberto pela comunidade abrangente para a formação de sujeitos mais éticos, na busca do diálogo constante na construção coletiva de uma cidade que abriga as diferenças, as igualdades, as identidades, as lógicas, desejos, erros, acomodando numa estética criativa, os projetos individuais e coletivos que enraízam no patrimônio conservado, a arte de viver a efemeridade do tempo.

\section{Fechando este testemunho}

Ao refletir-se sobre a importância etnográfica e social do conjunto arquitetônico em questão, poder-se-ia argumentar porque não aderir privilegiadamente à destruição patrimonial uma vez que a re-criação e inovação é ato sistemático e re-inventivo da condição humana. Talvez a razão mais lógica seja a afetiva se recorrermos a Walter Benjamin e seu conceito de memória involuntária retirado da obra de Proust. É porque conhecer a história da cidade e no caso da história da cidade universitária é poder enraizar em territórios de pertencimento, em espaços vividos, o nosso sentimento de pertença, nossa consciência de autoria em uma cidade histórica, que abriga sua memória coletiva. Ao mesmo tempo, o direito à consciência do nosso passado, permite o fluxo temporal das re-invenções cotidianas, das alteridades geracionais que compartilham na descontinuidade temporal, as marcas patrimoniais de valores arraigados e referências identitárias, uma vez que a cultura é dinâmica e se transforma no processo histórico de indivíduos e grupos sociais. 
Se o papel da Universidade é a vitalização da aprendizagem, o fomento do ensino e a transmissão do saber, importa acentuar que sua materialidade não abriga apenas uma infra estrutura sempre insuficiente, sempre em projeto, sempre em construção, mas é onde habitam as imagens de pertença, de trajetória, de histórias cidadãs, de relação com a dinâmica da cidade que se transforma.

Reformar prédios abandonados frente as dificuldades de um país marcado pela desigualdade pode parecer contraditório se não atentarmos para as razões simbólicas de um povo durar na sua cultura singular. Nossa civilização ocidental se inscreve humanitariamente nestas produções arquitetônicas, que permitem fazer durar os códigos e sentidos de existência que futuras gerações certamente merecem herdar.

\section{REFERÊNCIAS:}

BENJAMIN, Walter. "Sobre alguns temas em Baudelaire". In: Charles Baudelaire um lírico no auge do capitalismo. Obras escolhidas volume III. SP, Ed. Brasiliense

DE CERTEAU, Michel. A invenção do cotidiano: artes de fazer. Petrópolis, Vozes, 1994 ELIADE, Mircea. Mito do eterno retorno. SP, Mercuryo, 1992.

Folder O Patrimônio Histórico é de todos nós. UFRGS. Secretaria do Patrimônio Histórico da UFRGS.

GUEDES, Paulo Coimbra e SANGUINETTI, Yvonne (Organizadores). UFRGS Identidade e memórias. Porto Alegre, Editora da Universidade, 1994.

HASSEN, Maria de Nazareth Agra (Org). Escola de Engenharia/UFRGS - UM SÉCULO. Porto Alegre, Tomo Editorial, 1996.

HASSEN, Maria de Nazareth Agra. Fogos de Bengala nos céus de Porto Alegre. A Faculdade de Medicina faz 100 anos. Livro comemorativo ao centenário da Faculdade de Medicina da Universidade Federal do Rio Grande do Sul 1898-1998. Porto Alegre, Tomo Editorial, 1998.

LEITE, Denise et alli. Universidade e ensino de graduação. Memória e caracterização na UFRGS e na UFPEL. Pelotas, Editora da UFPel, 1996

LEITE, Luiz Osvaldo. "Instituto de Filosofia e Ciências Humanas - Subsídios Históricos". In: IFCH publicação comemorativa. 50 anos Filosofia e Ciências Humanas, 1943-1993. Porto Alegre, Rio Grande do Sul, UFRGS, 1993. p. 81 a 104. 